\title{
The pebble fines contribution into radiation environment of the river Yenisei floodplain in an influence zone of the Krasnoyarsk mining and chemical combine (KMCC)
}

\author{
F.V. Sukhorukov, M.S. Melgunov and A.V. Chuguevskii \\ V.S.Sobolev Institute of geology and mineralogy SB RAS, Novosibirsk, \\ pr. ac. Koptyuga, 3, Russia
}

\begin{abstract}
The results of investigation of radioactive contamination of the river Yenisei bed pebbles in an influence zone of the KMCC (especially in its near-field part) are presented in this work. It is demonstrated, that pebbles can contain up to $30 \%$ of the total amount of $\gamma$-emitting technogenic radionuclides (TRN) in the places with overlying soils. In addition, river bed pebbles, situated in permanently washing riverside sections of islands and banks, can contain significant amount of TRN too. These facts considerably increase an estimation of TRN reserves in the Yenisei floodplain. Without the contribution of the river bed pebbles the fraction of TRN, accumulated in the underlying and tow path pebbles in the near and far-field influence zones of the KMCC, can reach 7,9\% for ${ }^{137} \mathrm{Cs}, 5,8 \%$ for ${ }^{152} \mathrm{Eu}, 5,6 \%$ for ${ }^{154} \mathrm{Eu}$ and $<3 \%$ for ${ }^{60} \mathrm{Co}$ of their total amount.
\end{abstract}

\section{INTRODUCTION}

The main radioactive contamination of the river Yenisei floodplain is bound up with activity of the Krasnoyarsk mining and chemical combine (KMCC). Numerous data on contamination of the Yenisei floodplain by $\gamma$-, $\beta$ - and $\alpha$-emitting TRN concern water, alluvial soils of islands and right-hand riverbank, bottom sediments presented by sandy and sandy-argillaceous structures, aqueous and surface plants, fishes [1-6]. Now the main dose generating $\gamma$-emitting TRN are long-living isotopes ${ }^{137} \mathrm{CS},{ }^{152} \mathrm{Eu},{ }^{154} \mathrm{Eu}$ and ${ }^{60} \mathrm{Co}$. At the moment there is no sufficient information on presence of the TRN in river pebbles and especially in its fines. The possibility of radioactive contamination of the river bed pebbles, including those underlying alluvial soils and bottom sediments, practically is not taken into account. Moreover, it is considered, that they are not contaminated by TRN because of their transit properties in relation to sandy and sandy-argillaceous bottom sediments [7]. However, still it was noticed by Nosov, etc [1], total activity of all TRN in the river pebbles in the near-field influence zone of the KMCC had not exceeded $40 \mathrm{kBq} / \mathrm{m}^{2}$. And it was associated basically with presence of benthos. The first information about presence of the TRN in the fines of pebbles, underlying alluvial soils on Atamanovsky island ( $6 \mathrm{~km}$ downstream from a point of KMCC discharge), was done by Sukhorukov, etc. [5, 6]. The study of an alluvial soil profile spent in this work has shown that pebbles underlay soil on depth more than $40 \mathrm{~cm} .{ }^{137} \mathrm{Cs},{ }^{152} \mathrm{Eu}$ and ${ }^{60} \mathrm{Co}$ were detected in pebble fines and activity of ${ }^{137} \mathrm{Cs}$ did not decrease with pebble occurrence depth.

The purpose of the present work is to estimate the contribution of underlying and river bed pebbles in the total contamination of the river Yenisei floodplain and its dependence on the distance from the point of the KMCC contaminated waters discharge.

\section{OBJECTS, SAMPLING AND METHODS}

The underlying, tow path and river bed pebbles of the river Yenisei can be divided conventionally on two components. The great bulk (more than $85 \%$ ) of them is presented as rounded pieces of rocks of 


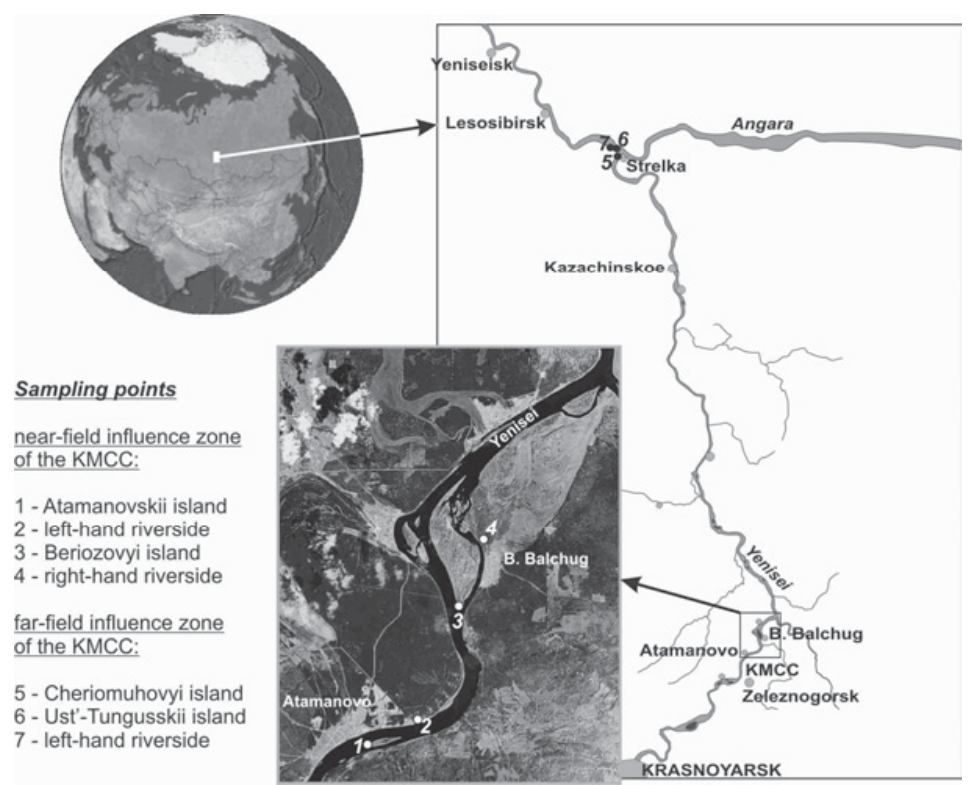

Figure 1. The region of investigations and location of sampling points.

sufficiently large size: cobblestones $(64-256 \mathrm{~mm})$ and pebbles exactly $(2-64 \mathrm{~mm})$. As a rule, the whole space between large pieces is filled up by fine-dispersed material: sand $(0,0625-2 \mathrm{~mm})$, silt $(0,002-$ $0,0625 \mathrm{~mm})$ and clay $(<0,002 \mathrm{~mm})$. This fine-dispersed material is termed as pebble fines. By its composition the pebble fines is close to alluvial soils and bottom sediments of the floodplain of the river Yenisei. Just as soils and bottom sediments, situated in the influence zone of the KMCC, the pebble fines here can be polluted by TRN too. For this reason the pebble fines is the basic subject of this study.

To estimate the contribution of fines of underlying, tow path and river bed pebbles to the total contamination of the floodplain of the river Yenisei the sampling has been carried out in 7 points on different distances from the discharge of the KMCC (Fig. 1, Table 1). All soil-pebbles and pebbles profiles chosen for study are typical for the specified territories.

\subsection{Sampling procedure}

Soils were sampling in layers on full depth of vertical soil profiles. To obtain a sample of the fixed volume the sampling was carried out by a steel ring $8,2 \mathrm{~cm}$ in diameter and $5 \mathrm{~cm}$ in height. Then the soil samples were packed and conveyed to laboratory where they were dried and prepared for measurement [6].

Procedure of a pebble fines sampling was consisted in the following. Material of pebbles was taken in layers from the preliminarily cleared area of a known square. Pebbles were washed out in large volume of Yenisei water. In a wet condition it was sifted through a $2 \mathrm{~mm}$ sift. Washed off cobbles and pebbles were moved away. The fine fraction was settled for 24 hours. Then water was cautiously poured out, the residual sample was packed and conveyed to laboratory where after drying and preparation all it volume was measured to determine activities of the gamma-emitting TRN.

\subsection{Analytical methods}

Determination of the $\gamma$-emitting TRN in soil and pebble fines samples was carried out by semi-conductor $\gamma$-spectrometry with use of HPGe and Ge (Li) coaxial detectors. Limits of detection of this method 
Table 1. Description of points where samples of the pebble fines were taken.

\begin{tabular}{|c|c|c|c|}
\hline $\begin{array}{c}\text { Point } \\
\text { Number }\end{array}$ & $\begin{array}{l}\text { Distance } \\
\text { from } \\
\text { KMCC } \\
\text { discharge }\end{array}$ & Location & Description \\
\hline \multicolumn{4}{|c|}{ Near-field influence zone of the KMCC } \\
\hline 1 & $6 \mathrm{~km}$ & Atamanovskii island & $\begin{array}{l}\text { vertical profiles on the right bank of the head of } \\
\text { the island: E-116 (1998, soil and pebble fines) } \\
\text { and } 100 \mathrm{~m} \text { downstream closely spaced } \\
\text { E-121 (1998, soils) and E-202 (1999, pebble fines) }\end{array}$ \\
\hline 2 & $7 \mathrm{~km}$ & Left-hand riverside & tow path pebbles, E-201 (1999, pebble fines) \\
\hline 3 & $16 \mathrm{~km}$ & Beriozovyi island & $\begin{array}{l}\text { vertical profile on the head of the island } \\
E_{07}-295 \text { ( } 2007 \text {, soil and pebble fines), } \\
\text { four pebble profiles on the uncovered river bed: } \\
E_{08}-337, E_{08}-338, E_{08}-339, E_{08}-341 \\
(2008 \text {, pebble fines) }\end{array}$ \\
\hline 4 & $18 \mathrm{~km}$ & $\begin{array}{l}\text { Right bank, } \\
\text { Balchug branch }\end{array}$ & $\begin{array}{l}\text { closely spaced vertical profiles on the } \\
\text { right bank of Balchug branch: E-306,307 } \\
(2000, \text { soil) and E-203 (1999, pebble fines) }\end{array}$ \\
\hline \multicolumn{4}{|c|}{ Far-field influence zone of the KMCC } \\
\hline 5 & $250 \mathrm{~km}$ & Cheriomuhovyi island & $\begin{array}{l}\text { vertical profile on the head of the } \\
\text { island E-325 ( } 2000 \text {, soil and pebble fines) }\end{array}$ \\
\hline 6 & $256 \mathrm{~km}$ & Ust'-Tungusskii island & $\begin{array}{l}\text { closely spaced vertical profiles } \\
\text { on the head of the island: E-329 }(2000, \text { soil }) \\
\text { and E-332 (2000, pebble fines) }\end{array}$ \\
\hline 7 & $257 \mathrm{~km}$ & Left-hand riverside & tow path pebbles, $\mathrm{E}_{07}-302$ (2007, pebble fines) \\
\hline
\end{tabular}

*) Hereinafter a year of sampling is given in brackets.

were: $2 \mathrm{~Bq} / \mathrm{kg}$ for ${ }^{152} \mathrm{Eu},{ }^{154} \mathrm{Eu},{ }^{137} \mathrm{Cs}$ and ${ }^{60} \mathrm{Co}$ and $10 \mathrm{~Bq} / \mathrm{kg}$ for ${ }^{40} \mathrm{~K}$. A measurement error was $30-10 \%$ ( $2 \sigma$ criterion) for activities more than 10 and $50 \mathrm{~Bq} / \mathrm{kg}$ accordingly.

\section{RESULTS AND DISCUSSION}

\subsection{TRN in soils and underlying pebbles}

Diagrams of the $\gamma$-emitting TRN distribution in vertical soil-underlying pebbles profiles for islands and right bank of the near-field influence zone of the KMCC are presented on the Fig. 2, for islands of the far-field zone - on the Fig. 3. Curves shapes underline some characteristic features of spatial distribution of the $\gamma$-emitting TRN in alluvial soils the Yenisei floodplain. The basic tendencies here are reduction of radioactive contamination density and increase of ${ }^{137} \mathrm{Cs}$ contribution to the total contamination of alluvial soils by moving away from the discharge point of the $\operatorname{KMCC}[1,6]$. It is necessary to draw attention to the extremely non-uniform distribution of the TRN in all studied profiles. On this background the behavior of natural ${ }^{40} \mathrm{~K}$ has much more uniform character. It indicates the similarity of mineral composition of soils lying down on different horizons.

The contaminated alluvial soils of the near-field influence zone of the KMCC (Fig. 2) are characterised by considerable content of the main dose generating $\gamma$-emitting TRN in all layers of the studied soil profiles down to the underlying pebbles. This fact says that these soils here have been generated in the period of the KMCC activity. The contribution of europium isotopes $\left({ }^{152} \mathrm{Eu}\right.$ and $\left.{ }^{154} \mathrm{Eu}\right)$ to the total contamination in the studied soil profiles varies from dominating (Fig. 2a) to considerable 


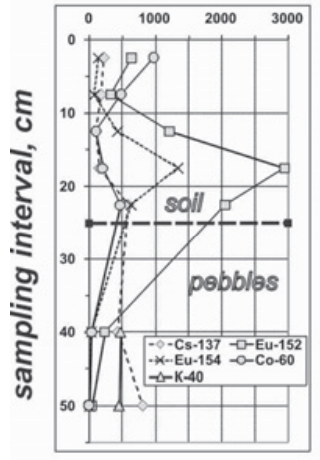

a)

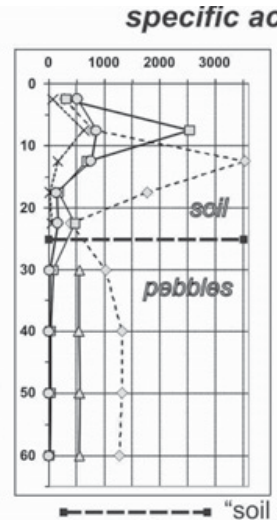

b)

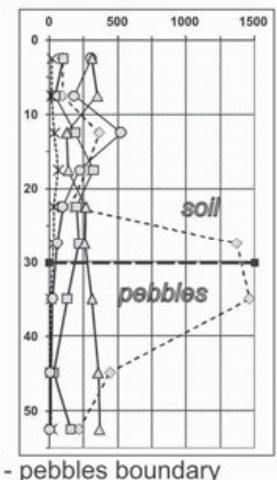

c)

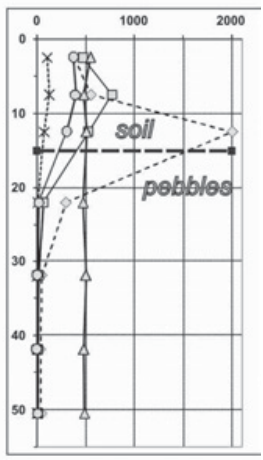

d)

Figure 2. Distribution of $\gamma$-emitting TRN in vertical profiles of soils and pebble fines in the near-field influence zone of the KMCC (Table 1): a) Atamanovskii island (point 1, E-116); b) Atamanovskii island (point 1, E-121 and E-202); c) Beriozovyi island (point 3, $\mathrm{E}_{07}-295$ ); d) Balchug branch (point 4, E-306,307 and E-203).

specific activity, Bq/kg

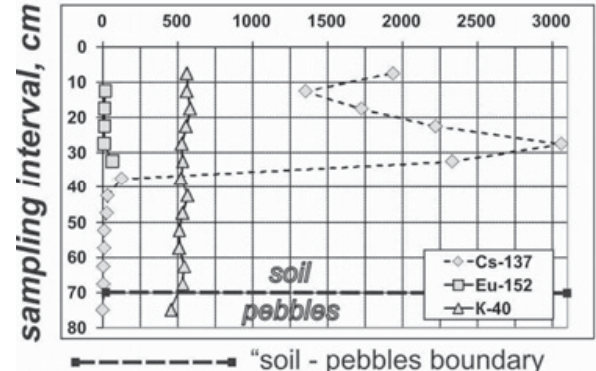

a)

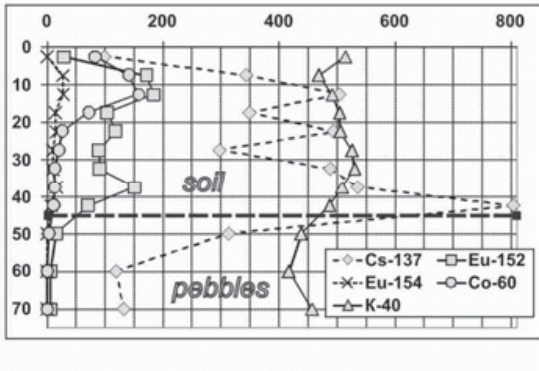

b)

Figure 3. Distribution of $\gamma$-emitting TRN in vertical profiles of soils and pebble fines in the far-field influence zone of the KMCC (Table 1): a) Ust'-Tungusskii island (point 6, E-329 and E-332); b) Cheriomuhovyi island (point 5, E-325).

(Figs. 2b-d). The last three soil profiles are characterised by considerable contribution of ${ }^{137} \mathrm{Cs}$ which essentially increases in the lower layers of the soils laying directly on the underlying pebbles or locating close to them.

Contamination of alluvial soils of islands in the far-field influence zone of the KMCC by $\gamma$-emitting TRN has different character (Fig. 3). Here dominating is ${ }^{137}$ Cs. On island Cheriomuhovyi (Fig. 3b) radioactive contamination is observed across the whole soil profile down to the underlying pebbles. Besides the main dose generating radionuclide ${ }^{137} \mathrm{Cs}$ isotopes ${ }^{152} \mathrm{Eu}$ and ${ }^{60} \mathrm{Co}$ are presented here at significant and ${ }^{154} \mathrm{Eu}$ in minor quantities. It is obvious, that soils here have been generated after the beginning of operation of the KMCC too. The Ust-Tungusskii island is situated in $6 \mathrm{~km}$ downstream from island Cheriomuhovyi after Angara inflow to the Yenisei river. The Angara stream moves the Yenisei waters to the left riverside. Only ${ }^{137} \mathrm{Cs}$ and trace quantities of ${ }^{152} \mathrm{Eu}$ are present in the soil profile selected on the Ust-Tungusskii island (E-329 and E-332, Fig. 3a). Practically all activity of ${ }^{137} \mathrm{Cs}$ is concentrated in the upper soil horizons $(30-35 \mathrm{~cm})$. It decreases dramatically below $(35-55 \mathrm{~cm})$ and tends to background values in the horizons laying directly on the underlying pebbles. Such character of the TRN distribution directly specifies that the lower horizons of alluvial soils here have been formed prior to the beginning of the KMCC activity. 
Table 2. Activity of the $\gamma$-emitting TRN in the fines of underlying pebbles: the head of Beriozovyi island (point 3, $\mathrm{E}_{07}-295$, Table 1, Fig. 2c).

\begin{tabular}{|l|c|r|r|r|r|r|c|}
\hline \multirow{2}{*}{ Probe } & \multirow{2}{*}{ Sampling interval, cm } & \multirow{2}{*}{ Weight, $\mathrm{g}$} & \multicolumn{5}{|c|}{ Specific activity, Bq/kg } \\
\cline { 4 - 8 } & & & ${ }^{137} \mathrm{Cs}$ & ${ }^{152} \mathrm{Eu}$ & ${ }^{154} \mathrm{Eu}$ & ${ }^{60} \mathrm{Co}$ & ${ }^{40} \mathrm{~K}$ \\
\hline $\mathrm{E}_{07}-295 / 1$ & $30-40$ & 1398,7 & 1468,4 & 129,2 & 13,1 & 16,9 & 310,8 \\
\hline $\mathrm{E}_{07}-295 / 1 \mathrm{~m}^{*)}$ & $30-40$ & 853,7 & 3153,3 & 313,1 & 27,8 & 24,6 & 259,3 \\
\hline $\mathrm{E}_{07}-295 / 2$ & $40-50$ & 1216,5 & 445,6 & 29,6 & 7,0 & 5,4 & 357,1 \\
\hline $\mathrm{E}_{07}-295 / 2 \mathrm{~m}^{*)}$ & $40-50$ & 244,1 & 2021,7 & 157,3 & 15,5 & 8,7 & 303,2 \\
\hline $\mathrm{E}_{07}-295 / 3$ & $50-55$ & 1092,2 & 217,5 & 3,7 & $<2$ & $<2$ & 368,6 \\
\hline
\end{tabular}

*) $<0,01 \mathrm{~mm}$ fraction of the respective pebble fines samples

Diagrams of the TRN distribution in vertical soil-underlying pebbles profiles, shown on Figs. 2 and 3, indicate that not only soils, but also fines of the pebbles have been radioactively contaminated. Except for E-329-E-332 profile (Fig. 3a) where the upper layer of the pebbles, as well as the lower horizons of soil, is not contaminated by the TRN. Contamination of the pebble fines by the TPN is observed on the full studied depth of the pebbles $(25-35 \mathrm{~cm})$. In all profiles it does not approach to background values though the trend of a decrease of its level from upper horizons of the pebbles to the lower one is obviously observed. The important characteristic of radioactive contamination of the pebble fines is the dominance of ${ }^{137} \mathrm{Cs}$. It is observed in all studied profiles, even where Eu isotopes (Fig. 2) are dominating in soils.

The data submitted in Table 2, show, that the fine-dispersed fraction of the pebble fines $(<0.01 \mathrm{~mm})$ from Beriozovyi island, presented basically by clay minerals, is considerably enriched by TRN in comparison with its other part. So, specific activity of the fine fraction is more than 2 times higher for ${ }^{137} \mathrm{Cs},{ }^{152} \mathrm{Eu}$ and ${ }^{154} \mathrm{Eu}$.

\subsection{TRN in tow path and river bed pebbles}

In points 2 and 7 (Table 1) the study of the $\gamma$-emitting TRN distribution in fines of the upper horizons of the tow path pebbles of the Yenisei left-hand riverside was carried out. The results are given in the Table 2. It is obvious, that in the near-field influence zone of the KMCC (point 2, profile E-201) only ${ }^{137} \mathrm{Cs}$ is presented $(7 \mathrm{~Bq} / \mathrm{kg})$ in pebble fines. This level corresponds to a global background and indicates on the absence of the radioactive contamination of the left-hand riverside in the near-field zone. In the far-field influence zone (point 7, profile $\mathrm{E}_{07}-302$ ) higher activity of ${ }^{137} \mathrm{Cs}$ and presence of ${ }^{60} \mathrm{Co}$ are observed in the fines of the tow path pebbles. It denotes presence of radioactive contamination of the left-hand riverside connected with the movement of the Yenisei waters to the left-hand by Angara.

In the near-field influence zone of the KMCC the main river bed pebbles were studied too. As the tow path pebbles they also are uncovered by soils. Four profiles $\left(\mathrm{E}_{08}-341, \mathrm{E}_{08}-339, \mathrm{E}_{08}-338, \mathrm{E}_{08}-337\right.$, point 3, Table 1) have been sampled in 2008 in the head of the island Beriozovyi at extremely low water level in Yenisei on distances of 3, 12, 20, $50 \mathrm{~m}$ from a river bank line accordingly. In normal conditions these pebbles are covered by water and washed out by the stream of Yenisei. The results of TRN determination in fines of these pebbles are presented in Table 3. It is evidence, that the river bed pebbles in these profiles are contaminated by TRN on the full studied depth as well as the pebbles on the banks covered by soils. Distinctive feature here is the considerable contribution of Eu isotopes to the general contamination, comparable with the contribution of ${ }^{137} \mathrm{Cs}$. 
Table 3. Activity of the $\gamma$-emitting TRN in the pebble fines: the left-hand riverside of Yenisei.

\begin{tabular}{|c|c|c|c|c|c|c|c|c|}
\hline \multirow{2}{*}{ Probe } & \multirow{2}{*}{ Sampling interval, cm } & \multirow{2}{*}{ Weight, g } & \multicolumn{7}{|c|}{ Specific activity, Bq/kg } \\
\cline { 4 - 9 } & & & ${ }^{137} \mathrm{Cs}$ & ${ }^{152} \mathrm{Eu}$ & ${ }^{154} \mathrm{Eu}$ & ${ }^{60} \mathrm{Co}$ & ${ }^{40} \mathrm{~K}$ \\
\hline E-201/1 & $0-10$ & 2087,6 & 7 & $<2$ & $<2$ & $<2$ & 464 \\
\hline E-201/2 & $10-20$ & 1309,6 & 7 & $<2$ & $<2$ & $<2$ & 480 \\
\hline \multicolumn{7}{|c|}{ Point 2 (Table 1) } \\
\hline $\mathrm{E}_{07-302}$ & $0-10$ & 1209 & 17 & $<2$ & $<2$ & 6 & 332 \\
\hline
\end{tabular}

Table 4. Activity of the $\gamma$ - emitting TRN in the pebble fines: the main river bed near the head of Beriozovyi island (point 3, $\mathrm{E}_{08}-341, \mathrm{E}_{08}-339, \mathrm{E}_{08}-338, \mathrm{E}_{08}-337$, Table 1).

\begin{tabular}{|c|c|r|r|r|r|r|c|}
\hline \multirow{2}{*}{ Probe } & \multirow{2}{*}{ Sampling interval, $\mathrm{cm}$} & \multirow{2}{*}{ Weight, $\mathrm{g}$} & \multicolumn{5}{|c|}{ Specific activity, Bq/kg } \\
\cline { 4 - 8 } & & & ${ }^{137} \mathrm{Cs}$ & ${ }^{152} \mathrm{Eu}$ & ${ }^{154} \mathrm{Eu}$ & ${ }^{60} \mathrm{Co}$ & ${ }^{40} \mathrm{~K}$ \\
\hline $\mathrm{E}_{08}-341 / 1$ & $0-5$ & 2256,8 & 129,9 & 180,4 & 38,4 & 88,7 & 559,1 \\
\hline $\mathrm{E}_{08}-341 / 2$ & $5-10$ & 1782,2 & 156,1 & 282,1 & 50,0 & 145,5 & 594,3 \\
\hline $\mathrm{E}_{08}-341 / 3$ & $10-15$ & 1070,4 & 136,5 & 114,5 & 19,4 & 81,9 & 553,1 \\
\hline $\mathrm{E}_{08}-341 / 4$ & $15-20$ & 744,8 & 415,3 & 198,6 & 21,0 & 39,8 & 558,4 \\
\hline $\mathrm{E}_{08}-339 / 1$ & $0-5$ & 1215,2 & 263,3 & 59,7 & 13,4 & 43,6 & 505,2 \\
\hline $\mathrm{E}_{08}-339 / 2$ & $5-10$ & 1668,8 & 396,8 & 220,4 & 21,3 & 34,4 & 568,8 \\
\hline $\mathrm{E}_{08}-339 / 3$ & $10-23$ & 1236,6 & 1170,3 & 194,0 & 17,3 & 19 & 513,3 \\
\hline $\mathrm{E}_{08}-338 / 2$ & $0-8$ & 2015,8 & 130,6 & 206,6 & 38,4 & 48,5 & 496,7 \\
\hline $\mathrm{E}_{08}-338 / 2$ & $8-20$ & 1241,9 & 273,5 & 109,8 & 15,1 & 42,9 & 474,8 \\
\hline $\mathrm{E}_{08}-337 / 1$ & $0-8$ & 1272,6 & 155,8 & 74,6 & 12,7 & 49,9 & 482,7 \\
\hline $\mathrm{E}_{08}-337 / 2$ & $0-25$ & 1499,2 & 84,3 & 167,0 & 25,1 & 79,3 & 575,7 \\
\hline
\end{tabular}

\subsection{TRN storages in the Yenisei pebbles}

Taking into account the presence of significant amount of TRN in the fines of the underlying, river bed and tow path pebbles leads to revaluation of their storage deposited in alluvial formations of Yenisei in the influence zone of KMCC towards increase. For example, on the island Beriozovyi (point 3, profile $\mathrm{E}_{07}-295$, Table 1) $40,8 \%$ of ${ }^{137} \mathrm{Cs}, 13 \%$ of ${ }^{152} \mathrm{Eu}, 8,2 \%$ of ${ }^{154} \mathrm{Eu}$ and $1,3 \%$ of ${ }^{60} \mathrm{Co}$ of their total storage in this point are concentrated in the pebble fines. The same it is possible to observe in the pebbles of the island Atamanovskii (point 1, E-116, Table 1) where a fraction of ${ }^{137} \mathrm{Cs}$ in its total amount in the soil-underlying pebbles system is equal to the value of $\sim 30 \%$. Some estimations show, that without the contribution of the river bad pebbles the fraction of TRN, accumulated in the underlying and tow path pebbles in the near-field and far-field influence zones of the $\mathrm{KMCC}$, can reach 7,9\% for ${ }^{137} \mathrm{Cs}, 5,8 \%$ for ${ }^{152} \mathrm{Eu}, 5,6 \%$ for ${ }^{154} \mathrm{Eu}$ and $<3 \%$ for ${ }^{60} \mathrm{Co}$.

\section{References}

[1] Nosov A.V., Ashanin N.V., Ivanov A.B., Martynova A.M. Atomic Energy 74 iss. 2 (1993) 144-150 (in Russian).

[2] Vakulovsky S.M., Tertyshnik E.G., Borodina T.S., Iskra A.A., "Man-maid radionuclides in the Yenisiy river", Radioactivity after nuclear explosions and accidents, Moscow December, 
5-6 2005, Yu. A. Izrael' Eds. v. 2 (GIDROMETEOIZDAT, St.-Pitersburg, 2006) pp. 294-299 (in Russian).

[3] Kuznetsov Yu.V., Revenko Yu.A., Legin K.V. et al., Radiochemistry 36 (1994) 546-559 (in Russian).

[4] Sukhorukov F.V., Melgunov M.C., Kovalev S.I., Siberian Ecological J. 1 (2000) 39-50 (in Russian).

[5] Sukhorukov F.V., Melgunov M.C., Kovalev S.I., "Some peculiarities of distribution of anthropogenic radionuclides in alluvial soils and bottom sediments of the river Yenisei in the neighbourhood of Krasnoyarsk mining chemical plant", Radioactivity after nuclear explosions and accidents, Moscow April, 24-26 2000, v. 1 (GIDROMETEOIZDAT, St.-Pitersburg, 2000) pp. 537542 (in Russian).

[6] F.V. Sukhorukov, A.G. Degermendzhy, V.M. Belolipetsky, A.Ya Bolsunovsky, S.I. Kovalev, K.U. Kosolapova, M.S. Melgunov, V.F. Raputa. Distribution and migration of radionuclides in the Yenisei plain (Novosibirsk: Publ. House of SB RAS, Dep. “Geo”, 2004) 286 p. (in Russian).

[7] Linnik V.G., Surkov V.V., Potapov V.N., Volosov A.G., Korobova E.M., Borghuis A., and Brown J.E. Russian Geology and Geophysics v. 45 (2004) 1172-1187. 